\title{
GESTÃO DO CUSTO DA QUALIDADE NAS EMPRESAS QUIIMICAS DO BRASIL
}

RESUMO

Este artigo trata da análise do sistema de gestão do custo da qualidade nas indústrias químicas associadas à Abiquim (Associação Brasileira da Indústria Química e de Produtos Derivados). Os dados coletados foram tratados pelas técnicas da estatística descritiva e da análise fatorial. Os resultados evidenciaram

que o sistema de gestão do custo da qualidade: a) em 39\% das empresas estava incorporado ao sistema de gestão de negócios; b) não era utilizado como ferramenta de apoio para as decisões estratégicas; c) tinha a categoria de custo de falhas externas como a mais significativa; e d) não ocupava posição de destaque, mesmo para empresas que tinham sistema de garantia da qualidade implantado. Esses fatos revelaram oportunidades para o aprimoramento dos processos de gestão e de valorização profissional voltados para a qualidade, objetivando a competitividade por meio da minimização dos custos operacionais ou pela maximização dos níveis da qualidade dos serviços prestados aos clientes.

\section{Roberto Giro Moori \\ Mackenzie \\ Rubens Vieira da Silva \\ Mackenzie}

\begin{abstract}
This article dealt with the analysis of the quality cost system management in the chemical industries associated to Abiquim (Associação Brasileira da Indústria Quimica e de Produtos Derivados). The collected data were treated by tools of descriptive statistical and factorial analysis. The results showed that: a) 39\% of companies had quality cost system management incorporated in the corporative system management; $b$ ) it was not utilized as support tools to strategical decision; c) it had cost external failure category as the most significant; d) it had no relevant position, even in companies that had implemented quality assurance system. These facts revealed opportunities to improve the management process and profissional values geread towards to the quality, focusing the competitiveness through operational cost minimization or by maximizing quality service level desired by clients.
\end{abstract}

PALAVRAS-ChAVE Gestão do custo da qualidade, Abiquim, custo de prevenção, custo de falhas, custo de avaliação. KEY WORDS Quality cost management, Abiquim, prevention cost, failure cost, evaluation cost. 


\section{INTRODUÇÃo}

No atual estágio da globalização da economia, existe um mercado caracterizado por elevado nível de competitividade, consumidores exigentes e imprevisíveis. O cliente espera receber o serviço ou produto segundo suas especificações e de acordo com os requisitos contratualmente estabelecidos. Muitas organizações satisfazem essas expectativas, e, naturalmente, isso leva a uma competição cada vez mais exacerbada. Conquistar e manter clientes requer uma compreensão do que eles valorizam e uma atenção especial aos processos pelos quais esse valor pode ser constantemente fornecido. Evidentemente, há uma equação, ou trade-off, entre o valor que os clientes percebem que estão obtendo e o preço que estão dispostos a pagar (Christopher, 1999). O desafio é identificar maneiras de aumentar o valor para o cliente. No campo da gestão da qualidade, há o reconhecimento de que os produtos e serviços devem "encantar" os clientes de forma a mantê-los, o que é somente possível por meio da oferta de produtos e de serviços da mais alta qualidade. Para Feigenbaum (1994), o objetivo da indústria competitiva consiste em fornecer produtos ou serviços com a qualidade projetada, desenvolvida, comercializada e mantida dentro dos menores índices de custo que possibilitem satisfação total do consumidor. Uma das finalidades de um programa de custeio para um sistema de gestão é fornecer à organização um instrumento capaz de avaliar sua eficácia, por meio de informações que suportem as decisões de planejamento e controle dos administradores empresariais. Robbins (2000, p. 42), ao relacionar eficácia com sucesso empresarial, afirma que a eficácia é essencialmente determinada pelo grau de sucesso com que a organização alcança suas metas, citando como critérios de eficácia mais comuns a produtividade, a flexibilidade organizacional, a satisfação do cliente e a qualidade.

Em direção à satisfação do cliente, foram elaboradas as normas internacionais ISO 9000 pela International Organization for Standardization, federação mundial de organismos nacionais de normatização, abrangendo aproximadamente cem países (SBQ, 1998, 1999, 2000, p. 13). Essas normas criaram um certo impacto mundial no comércio internacional e na implementação de sistemas da qualidade nas empresas. A relação que se estabelece entre cliente e fornecedor visa a dar garantias contratuais de que há um Sistema de Garantia da Qualidade implementado, assegurando a qualidade do produto ou serviço. Se um sistema de gestão da qualidade está voltado para os aspectos da qualidade das atividades e dos produtos ou serviços de uma organização, pode-se, então, colocar a seguinte questão: o sistema de mensuração de custo da qualidade está integrado aos sistemas de gestão de negócios vigentes?

Essa pergunta justifica-se no fato da importância dada à qualidade dos produtos e serviços prestados aos clientes, incorporada à certificação ISO $9000 / 1994$. No Brasil, segundo dados do Inmetro (2002), em 2000 e 2001 haviam 1.615 e 1.368 certificados válidos, respectivamente. Entretanto, para as empresas realmente interessadas em se destacar na área da qualidade, isso não é o suficiente. As empresas deverão ter como meta migrar da certificação ISO $9000 / 1994$ para a certificação ISO $9001 / 2000$, em vigor a partir de 2002 - agora, com foco em processos e resultados, em que a medição dos custos da qualidade passou a ser obrigatória.

Considerando-se que são diversos os campos de atividade empresarial, este estudo foi circunscrito ao segmento químico, inserido no Complexo Químico Brasileiro. Ao final de 1997, mais de $80 \%$ das empresas associadas à Abiquim já haviam obtido a certificação ISO 9000 /1994 (Abiquim, 1997, p. 13). Em 1999, existiam 134 empresas filiadas à associação.

Em 2000, o faturamento líquido do Complexo Químico Brasileiro atingiu US $\$ 43,6$ bilhões, ou aproximadamente 7,3\% do PIB (Abiquim, 2002). Comparando-se a outro importante segmento econômico brasileiro, a indústria automobilística no mesmo ano atingiu um faturamento líquido de US $\$ 20$, 0 bilhões (Anfavea, 2002). O PIB considerado para o ano 2000 foi de US $\$ 594,2$ bilhões (Abiquim, 2002).

Nesse contexto, o objetivo principal desta pesquisa foi verificar se o sistema de mensuração de custo da qualidade estava integrado ao sistema de gestão de negócios das companhias do setor químico brasileiro.

Como objetivos específicos, procurou-se conhecer se o sistema de mensuração dos custos da qualidade: 1) era considerado uma ferramenta de apoio para tomada de decisões; 2) possibilitava evidenciar mais significativamente a categoria de custos da qualidade; e 3) ocupava uma posição de destaque nos sistemas de gestão de negócios da empresa.

\section{REFERENCIAL TEÓRICO}

Qualidade é um termo que assume diferentes significados para as pessoas. Heizer e Hender (2001, p. 71) definem-na como o conjunto de elementos e características de um produto ou serviço que atendem às necessidades explícitas ou implícitas dos consumidores. A definição das expectativas de qualidade do produto ou serviço é fundamental para o planejamento de operações eficazes e efici- 
entes. Ao se considerar a qualidade dos produtos ou serviços como um dos critérios diferenciadores entre as empresas, traz-se o conceito de "reação em cadeia" - introduzido por Deming (1990, p. 2) em sua obra Out of the Crisis, publicada em 1986 - que relaciona qualidade, custos e rentabilidade. Crosby (1999, p. 133) cita que a finalidade de ser apurado o custo da qualidade, que Juran e Gryna (1991) denominam "custo da má qualidade", é chamar a atenção da gerência e proporcionar uma referência quantitativa, ou benchmark, para se verificar a melhoria da qualidade. Ao abordar a importância de mensurar o custo da qualidade ou constituir um sistema de informações voltado para o gerenciamento da qualidade total, Feigenbaum (1994) argumenta que os custos da qualidade constituem as bases para os investimentos provenientes dos programas da qualidade que visem a melhorias contínuas de processos de fabricação, aumento da lucratividade ou outros benefícios para as empresas.

Falconi Campos (1999, p. 3) relaciona os conceitos de produtividade, qualidade e custos com os termos "valor produzido" e "valor consumido", refletindo a taxa de valor agregado ou satisfação das necessidades dos clientes. Juran e Gryna (1991) e Feigenbaum (1994) classificam o custo da qualidade em categorias que se inter-relacionam. Para Feigenbaum (1994), os custos da qualidade nas empresas devem ser considerados em duas categorias principais: a categoria dos custos de controle e a dos custos de falhas no controle. A categoria dos custos de controle é classificada em custos de prevenção e de avaliação. A categoria dos custos de falhas no controle é classificada em custos decorrentes de falhas internas e de falhas externas.

- Os custos de prevenção são os custos incorridos para evitar produtos ou serviços de qualidade inferior, tais como custos de educação, de treinamento, de atividades em simpósios de qualidade e outros.

- Os custos de avaliação são os custos de inspeções e de testes para a garantia de que os produtos estejam dentro das especificações, a fim de que não seja necessário trabalho adicional.

- Os custos de falhas internas são os custos devidos a defeitos ou falhas que ocorrem antes da entrega dos serviços ou da expedição dos produtos aos clientes.

- Os custos de falhas externas são os custos de produtos devolvidos, descontos e garantias dadas em face de produtos defeituosos entregues aos clientes.

Desses custos, os de prevenção e de avaliação são custos voluntários incorridos e podem ser controlados por decisão da empresa. Os custos de falhas internas e externas são involuntários incorridos como resultados de fa- lhas. É importante separá-los, porque os custos de falhas são dramaticamente diferentes para as falhas detectadas interna e externamente. Segundo Sakurai (1997, p. 135), os custos de falhas muitas vezes são 500\% mais elevados que os custos de controle. Juran e Gryna (1991, p. 99) alertam que os elementos constituintes de uma determinada categoria de custos podem mudar com o tempo. Além disso, ressaltam que a identificação dos elementos de custos pode causar discussões entre os administradores, pois alguns elementos não estão relacionados à qualidade, mas são custos que fazem parte das despesas operacionais normais e, portanto, não devem ser incluídos. Um exemplo: se a sucata originada na produção de um bem fizer parte de seu processo de fabricação, deve ser considerada como um custo de qualidade?

Os custos da má qualidade afetam tanto o fabricante como o cliente. Os custos do cliente são afetados na forma de custos de reparo após a garantia, perdas avariadas por causa do tempo parado etc.

Com isso, há atualmente a preocupação de incluir a identificação e a quantificação de outros custos associados à prevenção e à avaliação, e não somente aqueles ocasionados por falhas internas, que acarretam perdas de fabricação, falhas externas ou defeitos apresentados quando em uso pelo cliente.

A lógica sobre a gestão dos custos de controle da má qualidade deve ser liderada pela administração superior (Juran e Gryna, 1991, p. 103) para faciliar sua incorporação à gestão dos negócios da empresa, cuja estruturação dos dados pode seguir duas abordagens:

- desenvolver programas de custos de qualidade, usando posteriormente os resultados desses programas para identificar projetos específicos para o aperfeiçoamento;

- expandir o sistema contábil para quantificar os custos da qualidade e publicar os resultados na forma de um quadro demonstrativo contínuo.

Os objetivos dessas duas abordagens são idênticos. Entretanto, observam Juran e Gryna (1991), os números publicados e traduzidos em custos financeiros, por si só, não estimulam uma ação. É necessário que a empresa estabeleça um processo de gestão integrada aos negócios empresariais, estruturada para o aperfeiçoamento da qualidade e, por conseguinte, para sua almejada competitividade.

\section{METODOLOGIA}

A pesquisa foi conduzida dentro de uma amostra probabilística, uma vez que foram enviados questionários 
para todas as empresas associadas à Abiquim. Assim sendo, os resultados obtidos podem ser inferidos para toda a população dessas empresas químicas, ressalvando-se, contudo, algumas imperfeições geradas na operacionalização da pesquisa, como o tempo de execução e a acurácia dos dados. Predominaram as empresas de médio e grande porte do setor químico de base, produtos químicos e fibras sintéticas e artificiais.

A pesquisa foi realizada no último trimestre de 1999, e os dados foram obtidos por meio de um questionário fechado, enviado por correio, a todas as 134 empresas associadas à Abiquim. Cada questionário correspondeu a uma única empresa. A maioria dos respondentes ocupava cargo de gerente de qualidade. O questionário foi estruturado em três blocos: o primeiro consistiu, basicamente, na identificação da empresa pesquisada - seu preenchimento foi considerado opcional, pois foi constituído de informações como nome do respondente, endereço da empresa, telefone etc.; o segundo bloco, constituído de variáveis nominais, versou sobre a caracterização da empresa e o sistema de gestão de custo da qualidade - a obtenção das informações teve como base o método de enquetes, ou survey (Malhotra, 2001); no terceiro e último bloco, constituído de variáveis ordinais, as empresas foram solicitadas a indicar o grau de importância ou o valor de uma lista de atributos segundo uma escala do tipo Likert, com graduação de 1 a 5 para cada um dos elementos das categorias de custo da qualidade. Assim, a graduação 1 correspondeu à escala de importância "os custos envolvidos são sempre computados", a graduação 2 correspondeu a "os custos envolvidos são quase sempre computados", a graduação 3 a - "os custos envolvidos geralmente são computados", a graduação 4 a os "custos envolvidos raramente são computados" e a graduação 5 a "os custos envolvidos nunca são computados".

No total, foram elaboradas 35 assertivas, sendo 11 referentes aos elementos de custo da qualidade relacionadas à prevenção, nove referentes aos custos de avaliação, nove referentes aos custos de falhas internas e seis abordando elementos de custos da qualidade relacionados às falhas externas. Destaca-se que, para a empresa, o conjunto de perguntas desse último bloco foi apresentado de forma unificada, não explicitando a qual categoria de custo da qualidade a assertiva pertencia.

Para o tratamento dos dados coletados, utilizou-se: a) da estatística descritiva - a distribuição de frequêencias dos dados e a moda como medida de posição; b) da estatística inferencial - o qui-quadrado $\left(\chi^{2}\right)$ - para testar a hipótese de que as variáveis do sistema de mensuração de custos da qualidade e o sistema de apropriação são dependentes; e (c) da análise multivariada - a técnica da análise fatorial - para identificar fatores principais ou subjacentes em um conjunto de medidas realizadas.

\section{RESULTADOS}

\section{Caracterização das empresas e sistema de gestão de custos da qualidade}

De um total de 134 questionários enviados, o que correspondeu a toda população filiada à Abiquim, foram respondidos 55, sendo que uma das empresas enviou uma carta informando sua não-aplicabilidade, razão pela qual não foi considerado na análise estatística. Assim, foram tratados os dados de 54 questionários, parciais ou totalmente respondidos, representando $40,3 \%$ da população pesquisada.

Essa amostra apresentou algumas características consideradas importantes para a posterior análise dos resultados: a) 59\% das empresas apresentaram indicações para os 35 elementos de custos da qualidade pesquisados; b) 76\% das empresas eram certificadas pela ISO 9000 /1994; c) $66 \%$ das empresas atendiam exclusivamente o mercado interno e $34 \%$ das empresas atendiam o mercado interno e externo; d) $68 \%$ das empresas possuíam um sistema de gestão da qualidade implantado, $19 \%$ parcialmente implantado e $13 \%$ em fase de planejamento para implantação; e) $25 \%$ das empresas possuíam indicadores qualitativos (auditorias, informações de clientes e outros), somente $6 \%$ das empresas possuíam indicadores quantitativos de desempenho de qualidade, $42 \%$ das empresas possuíam indicadores de desempenho qualitativo e quantitativo com índices de qualidade, $23 \%$ das empresas possuíam indicadores de desempenho qualitativo, quantitativo e de custos de qualidade e $4 \%$ não possuíam indicadores de desempenho de nenhuma espécie; (f) 14\% das empresas possuíam um sistema de mensuração de custos da qualidade implantado, 20\% parcialmente implantado, $46 \%$ tinham a intenção de implantá-lo e 20\% não tinham, naquele momento, a intenção de implantá-lo; g) 30\% das empresas possuíam um centro de custos da qualidade integrado ao sistema contábil da empresa, 9\% das empresas possuíam centros de custos da qualidade específicos não integrados ao sistema contábil da empresa e $61 \%$ das empresas não possuíam um sistema de apropriação de custos da qualidade; e h) $27 \%$ das empresas geravam as informações de custo da qualidade para a melhoria do sistema da qualidade, $12 \%$ para avaliação do desempenho operacional, 27\% para melhoria do sistema e avaliação do desempenho, 12\% para melhoria do sistema, avaliação do desempenho e controle de custos, $8 \%$ para melhoria do sistema, controle de cus- 
tos e orçamento e $4 \%$ para todas as finalidades citadas.

Observa-se, na distribuição de freqüências dos dados, dois importantes resultados. O primeiro refere-se ao sistema de mensuração, identificado pelo item (f), e o segundo resultado refere-se ao sistema de apropriação, identificado pelo item (g). Assim, além da obtenção da distribuição de freqüências das variáveis individuais, interessou-se em fazer um estudo descritivo sobre o comportamento conjunto dessas duas importantes variáveis, isto é, verificar se a distribuição dos dados foi aleatória ou se existe uma associação ou dependência entre elas.

\section{Estatística indutiva para a gestão de custos da qualidade}

Utilizou-se da técnica do qui-quadrado $\left(\chi^{2}\right)$, cujos resultados são mostrados na Tabela 1 .

Observa-se na Tabela 1 que as variáveis do sistema de mensuração e do sistema de apropriação são estatisticamente relacionadas ou dependentes, pois $\chi^{2}$ Calculado $>\chi^{2}$ Crítico para o nível de significância $(\alpha)$ de $5 \%$.

Portanto, esse resultado evidencia que 39\% das empresas da amostra tinham um sistema de mensuração do custo da qualidade incorporado ao sistema de gestão de negó- cios, o qual se utilizava de sistema contábil ou centro de custo específico, conforme enfatizam Juran e Gryna (1991).

\section{Estatística descritiva para os elementos de custos da qualidade}

Os dados ordinais apurados por meio das assertivas do terceiro bloco do questionário foram tratados mediante distribuição de freqüências e da moda, como uma medida de tendência central.

\section{a) Custos de prevenção}

$\mathrm{Na}$ Tabela 2 são mostrados os resultados para os elementos de custo de prevenção.

Observa-se que o elemento mais significativo foi o programa de treinamento em qualidade do pessoal operacional, correspondente à assertiva 7, com 74\% das respostas assinaladas em (1) ou (2) na escala de valor, mostrando que esse seria um elemento sempre ou quase sempre considerado. Isso condiz com o estágio de implementação das normas ISO 9000 /1994, pois 76\% das empresas que responderam às assertivas desta pesquisa estão certificadas e o quesito treinamento é item obrigatório.

Do total de 11 elementos de custo componentes dessa

Tabela 1 - Distribuição das freqüências dos dados e teste do qui-quadrado $\left(\chi^{2}\right)$.

\section{SISTEMA DE APROPRIAÇÃO DOS CUSTOS DA QUALIDADE}

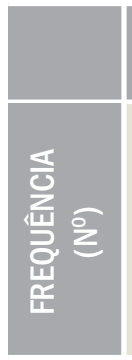

\section{(1) INTEGRADO AO SISTEMA CONTÁBIL}

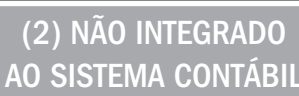

NÃO EXISTENTE

\section{TOTAL}

\begin{tabular}{|c|c|}
\hline \multirow{5}{*}{$\begin{array}{l}\text { Sistema de } \\
\text { mensuração } \\
\text { do custo da } \\
\text { qualidade }\end{array}$} & (1) implantado \\
\hline & (2) parcialmente implantado \\
\hline & (3) pretende implantar \\
\hline & (4) não pretende implantar \\
\hline & TOTAL \\
\hline \multirow{5}{*}{$\begin{array}{l}\text { Sistema de } \\
\text { mensuração } \\
\text { do custo da } \\
\text { qualidade }\end{array}$} & (1) implantado \\
\hline & (2) parcialmente implantado \\
\hline & (3) pretende implantar \\
\hline & (4) não pretende implantar \\
\hline & TOTAL \\
\hline
\end{tabular}

\begin{tabular}{|r|}
\hline 3 \\
\hline 5 \\
\hline \\
\hline 13 \\
\hline 23,1 \\
\hline 38,5 \\
\hline 38,5 \\
\hline 0,0 \\
\hline $\mathbf{1 0 0 , 0}$ \\
\hline
\end{tabular}

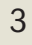

5

5

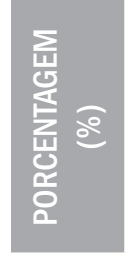

TOTAL

100,0
23,1

38,5

38,5

0,0

TESTE DO QUI-QUADRADO $\left(\chi^{2}\right)$

Coeficiente de Pearson $-\chi^{2}$ Calculado

Coeficiente de Pearson $-\chi^{2}$ Crítico

Nível de significância adotado $(\alpha)$

Graus de liberdade

Nível de significância (Asymp. Significance: 2-sided)

BASE DE DADOS (Válidos)

(Missing)
16,184

12,592 
categoria, sete constataram percentual acumulativo superior a $50 \%$ de respostas com valores (1) e (2) na escala de importância, correspondendo às assertivas 2, 4, 5, 7, 8, 9 e 11.

$\mathrm{Na}$ dispersão estatística observada para o elemento de custo da assertiva (1), 29\% das empresas sempre o consideram, total que atingiu $42 \%$ ao se incluir as respostas atribuídas ao valor (2) - quase sempre -, e 39\% raramente ou nunca o faziam.

Observação semelhante faz-se para o elemento de custo da assertiva 5 , em que $52 \%$ das empresas sempre ou quase sempre o consideravam e $41 \%$ raramente ou nunca o consideravam ou computavam.

Quanto à importância atribuída aos elementos identificados nas assertivas 2, 7 e 8, as respostas obtidas mostram distribuição de frequência acumulada igual ou superior a $80 \%$ já na escala (3) de valor, com os custos geralmente computados.

Com o cálculo estatístico da moda dos dados observados, pode-se inferir que há grupos de elementos com maior ou menor grau de importância na categoria de prevenção, com modas situadas entre $1 \leq x \leq 3$, sugerindo o tratamento fatorial desses dados para evidenciar fatores com direções comuns.

\section{b) Custo de avaliação}

Na Tabela 3 são mostrados os resultados para os elementos de custos de avaliação.

Os resultados obtidos com o tratamento de dados dos elementos representativos de custos de avaliação indicaram uma acentuada incidência de respostas no valor (1) da escala para os elementos representados pelas assertivas 14 e 16, esta última com a maior freqüência (58\%) verificada nesse grau de importância na escala. Seguem, por graus de importância, os elementos correspondentes às assertivas 12 e 13. Do resultado apurado dessas quatro assertivas, infere-se a existência do sistema de garantia da qualidade, evidenciado pela certificação ISO 9000/ 1994, presente em $76 \%$ das empresas que responderam à pesquisa. O baixo grau de importância atribuído às assertivas 18 e 19 , com $47 \%$ e $53 \%$ das respostas nos valores (4) e (5) da escala, respectivamente, de certa maneira foi surpreendente, devido à inferência da existência do sistema de garantia da qualidade, acima exposto.

\section{c) Custos de falhas internas}

$\mathrm{Na}$ Tabela 4 são mostrados os resultados para os elementos de custos de falhas internas.

\section{Tabela 2 - Custo da qualidade - Prevenção.}

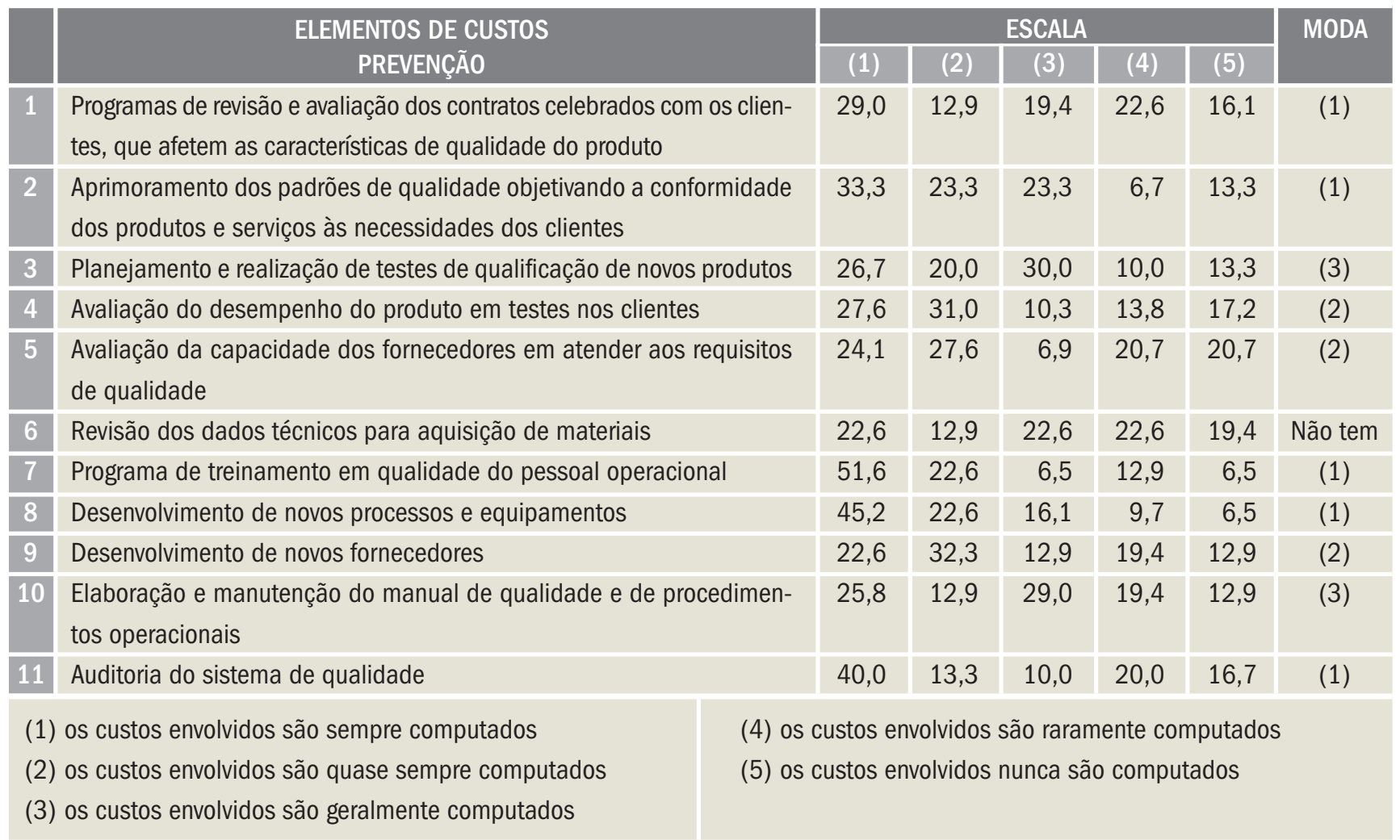


Quanto aos elementos de custo referentes às falhas internas, abordadas nas assertivas de 21 a 29, o resultado apurado evidenciou que existia, conforme o esperado, contabilidade dos custos decorrentes de perdas e refugo de produção. Esse fato é retratado na assertiva $21 \mathrm{com}$ $44 \%$ das respostas inseridas no valor (1) da escala, indicando serem sempre considerados os custos em questão, percentual que atinge $81 \%$ das respostas atribuídas até o grau (3) da escala. Observa-se, ainda, que esse elemento de custo é o que apresentou o maior valor para as freqüências obtidas dos elementos dessa categoria.

Com incidência semelhante de respostas aos graus de importância atribuídos, identificaram-se dois elementos inter-relacionados: retrabalho e mão-de-obra adicional decorrente desse retrabalho, apurados nas assertivas 22 e 23 . Ambos coincidiram no mesmo percentual da frequência acumulada, 53\%, ao se somarem os resultados atribuídos aos valores (1) e (2) na escala. O menor grau de importância observado dos elementos dessa categoria ocorreu na assertiva 26, evidenciado por $44 \%$ das respostas obtidas, indicando que raramente ou nunca esse elemento era considerado. As assertivas 27 e 28 apresentaram a mesma distribuição de frequências, podendo indicar um único fator de análise, pois o grau de importância dado a esses elementos de custos foi o mesmo, independentemente de as perdas por parada de unidade ou atrasos de produção serem devidos a falhas de operação ou de instrumentos de medida.

\section{d) Custos de falhas externas}

Na Tabela 5 são mostrados os resultados para os ele- mentos de custos de falhas externas.

A estatística descritiva dos elementos de custos decorrentes de falhas externas, aplicada às assertivas $30 \mathrm{a}$ 35, apresentou os seguintes resultados: a) o elemento de custo mais significativo foi evidenciado pela assertiva 34 , com 59\% das respostas atribuídas ao valor (1), sempre considerado na escala de importância; b) os custos devido à avaliação de produtos não-conformes devolvidos pelo cliente, assertiva 32, mostrou que esse elemento também era importante, com $59 \%$ das respostas obtidas no valor (1) da escala; c) em terceiro plano, mas muito próximo do anterior em grau de importância, situou-se o elemento de custo correspondente à substituição de produto não-conforme devolvido pelo cliente, evidenciado pela assertiva 31 , com 53\% das respostas atribuídas ao valor (1) da referida escala; d) entre os elementos da categoria redução das vendas em função de problemas de qualidade, assertiva 33, a oportunidade perdida defendida por Ostrenga et al. (1993) foi a que evidenciou o menor grau de importância na apuração dos custos, visto que $47 \%$ das empresas que responderam às perguntas desse bloco raramente ou nunca contabilizavam esse elemento.

Observa-se que os resultados apresentados nas Tabelas 2, 3, 4, e 5 deram-se com um grande número de variáveis. Entretanto, com a análise multivariada - a técnica de análise fatorial -, existe a possibilidade de identificar, a partir de um conjunto menor de variáveis, fatores principais ou subjacentes ao conjunto das medidas das variáveis realizadas. $\mathrm{Na}$ aplicação da análise fatorial, mostrada a seguir, foram

Tabela 3 - Custo da qualidade - Avaliação.

\begin{tabular}{|c|c|c|c|c|c|c|c|c|}
\hline & \multirow{2}{*}{\multicolumn{2}{|c|}{$\begin{array}{c}\text { ELEMENTOS DE CUSTOS } \\
\text { AVALIAÇÃO }\end{array}$}} & \multicolumn{5}{|c|}{ ESCALA } & \multirow[t]{2}{*}{ MODA } \\
\hline & & & (1) & (2) & $(3)$ & (4) & (5) & \\
\hline 12 & Testes de inspeção de matérias-primas & & 35,5 & 25,8 & 16,1 & 19,4 & 3,2 & (1) \\
\hline 13 & Inspeção de produto em processo & & 36,7 & 16,7 & 30,0 & 10,0 & 6,7 & (1) \\
\hline 14 & Análises de qualidade do produto acabado & & 54,8 & 12,9 & 19,4 & 6,5 & 6,5 & (1) \\
\hline 15 & Amostras de produto ou material consumidas no controle de qualic & idade & 25,8 & 16,1 & 16,1 & 29,0 & 12,9 & (4) \\
\hline 16 & Manutenção e calibração dos instrumentos de medida & & 58,1 & 12,9 & 16,1 & 9,7 & 3,2 & (1) \\
\hline 17 & Depreciação dos instrumentos de medida & & 29,0 & 19,4 & 19,4 & 16,1 & 16,1 & (1) \\
\hline 18 & Testes de qualificação dos produtos dos fornecedores & & 18,8 & 15,6 & 18,8 & 21,9 & 25,0 & (5) \\
\hline 19 & Testes da avaliação do desempenho do produto no cliente & & 21,9 & 12,5 & 12,5 & 28,1 & 25,0 & (5) \\
\hline 20 & Testes adicionais decorrentes de partidas de unidades de produç & & 32,3 & 6,5 & 25,8 & 22,6 & 12,9 & (1) \\
\hline $\begin{array}{l}(1) \\
(2) \\
(3)\end{array}$ & $\begin{array}{l}\text { os custos envolvidos são sempre computados } \\
\text { os custos envolvidos são quase sempre computados } \\
\text { os custos envolvidos são geralmente computados }\end{array}$ & $\begin{array}{l}\text { (4) } 0 \\
\text { (5) } 0\end{array}$ & istos & olvido & & comp & $\begin{array}{l}\text { putado } \\
\text { ados }\end{array}$ & \\
\hline
\end{tabular}

$42 \cdot$ oRAE $\cdot$ VOL. $43 \cdot \mathrm{N}^{\circ} 3$ 
adotados o critério Varimax with Kaizer Normalization, para maximizar a variância entre os fatores na rotação das matrizes fatoriais, e o KMO (Kaiser-Meyer-Olkin Measure of Sampling Adequacy), para verificar a adequação dos dados à análise fatorial.

\section{Análise fatorial para os} elementos de custo da qualidade

Aplicando a técnica de análise fatorial, têm-se: a) Elementos de custo de prevenção

Esses elementos foram contemplados na pesquisa, na análise fatorial denominada de componentes, pelas assertivas de números 1 a 11. Na Tabela 6 são mostrados os resultados.

O valor de KMO igual a 0,731 indica uma adequação razoável dos dados à análise fatorial. Há três fatores significativos para o grupo de elementos de custo de prevenção referentes aos valores de eigenvalues maiores do que 1 , re-

Tabela 4 - Custo da qualidade - Falhas internas.

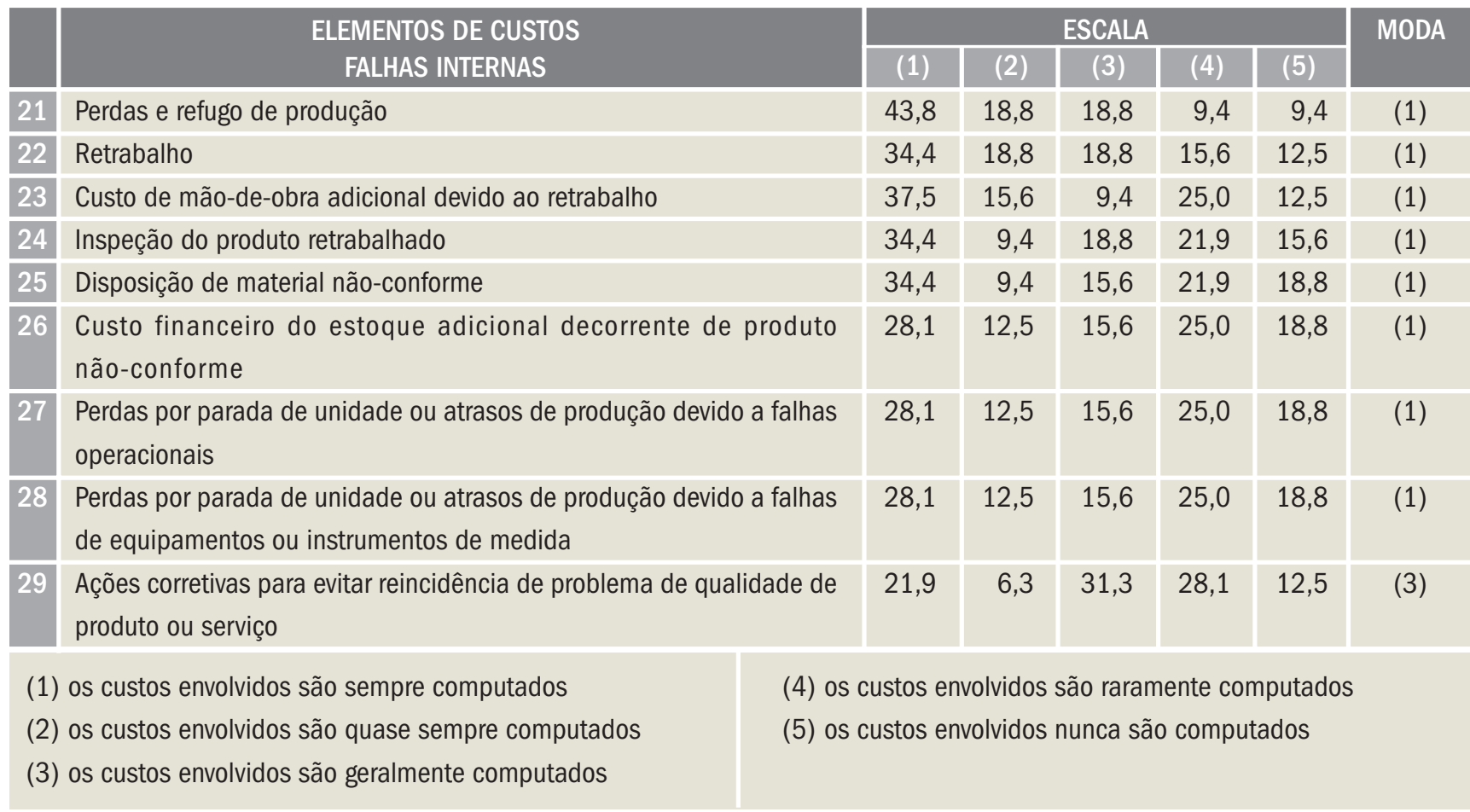

Tabela 5 - Custo da qualidade - Falhas externas.

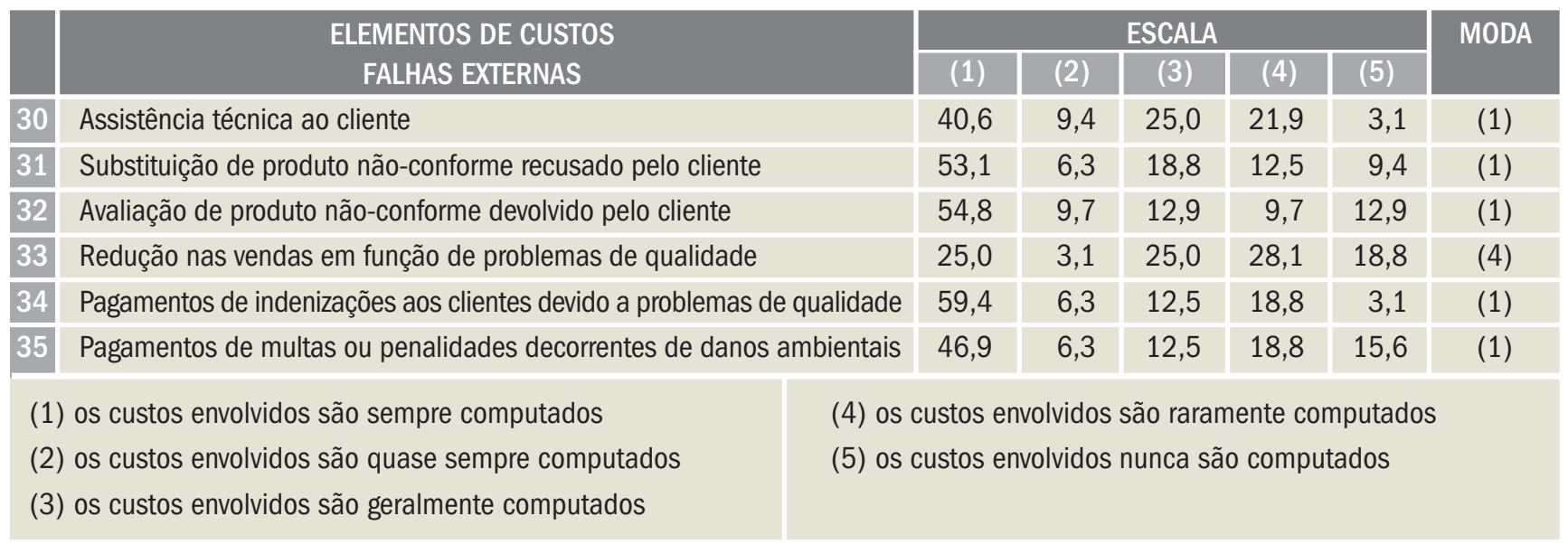


presentativos de $80 \%$ da variância do conjunto de dados originais, identificados na Tabela 6 , das cargas fatoriais da matriz rodada. Constata-se que o primeiro fator englobou cinco variáveis originais, as de números 2, 3, 4, 7 e 8 . Mediante os resultados obtidos, evidenciou-se que quatro delas estavam diretamente relacionadas com o grau de satisfação dos clientes, e a quinta, indiretamente, devido ao desenvolvimento de novos processos e equipamentos que influenciavam na melhoria do produto. Pode-se concluir que esse fator estava focado na satisfação do cliente, referindo-se à melhoria contínua dos processos e produtos. $\mathrm{O}$ segundo fator foi explicado por três variáveis, as de números 1, 5 e 6, que se referem aos custos decorrentes da avaliação da capacidade e do nível técnico de fornecedores. O terceiro fator foi evidenciado por três variáveis originais, as de números 9, 10 e 11, integrantes do sistema de gestão da qualidade, diretamente relacionadas com os requisitos da norma ISO $9000 / 1994$, lembrando que $76 \%$ das empresas respondentes eram certificadas.

No Quadro 1 estão os resultados da análise fatorial efetuada para esse grupo de elementos de custo de prevenção, destacando as variáveis principais, caracterizadoras dos fatores extraídos.

\section{b) Elementos de custo de avaliação}

Esses elementos foram contemplados na pesquisa, na análise fatorial denominada de componentes, pelas assertivas de números 12 a 20. Na Tabela 7 são mostrados os resultados.
O valor de $\mathrm{KMO}$ igual a 0,840 indica boa adequação dos dados à análise fatorial. Há dois fatores latentes no conjunto de elementos de custo de avaliação, identificados na Tabela 7 , das cargas fatoriais da matriz rodada, referentes aos valores de eigenvalues superiores a 1 , representativos de $72 \%$ da variância do conjunto de dados originais. Constata-se que o primeiro fator é constituído por quatro variáveis originais: a) testes de inspeção de matérias-primas; b) inspeção de produto em processo; c) análise de qualidade do produto acabado; d) manutenção e calibração dos instrumentos de medida; e e) testes adicionais decorrentes de partidas de unidades de produção.

A natureza dessas variáveis evidencia o custo operacional decorrente de análises em toda a linha produtiva, desde a matéria-prima até o produto final, incluindo os custos devido a aferição e calibração dos instrumentos de medida. Retrata, portanto, o custo de análise de conformidade aos requisitos especificados para matérias-primas e produtos em toda a cadeia operacional.

O segundo fator engloba as seguintes variáveis: a) amostras de produto ou material consumidas no controle da qualidade; b) depreciação dos instrumentos de medida; c) testes de qualificação dos produtos dos fornecedores; e d) testes de avaliação do desempenho do produto no cliente. Infere-se que as variáveis que compõem esse fator representam os custos de avaliação de desempenho de materiais e de produto. No Quadro 2 são mostrados os resultados da análise efetuada para esse grupo de elementos de custo de avaliação, destacando as variáveis originais principais, caracterizadoras dos fatores obtidos.

Tabela 6 - Custo de prevenção - Fator de carga (rotação: Varimax with Kaiser Normalization).

\begin{tabular}{|c|c|c|c|c|}
\hline COMPONENTES & FATOR 1 & FATOR 2 & FATOR 3 & COMMUNALITY \\
\hline 1 & 0,380 & $\mathbf{0 , 6 5 8}$ & 0,275 & 0,653 \\
\hline 2 & $\mathbf{0 , 7 5 4}$ & 0,188 & 0,435 & 0,792 \\
\hline 3 & $\mathbf{0 , 8 5 0}$ & 0,287 & 0,150 & 0,827 \\
\hline 4 & $\mathbf{0 , 8 7 2}$ & 0,358 & $6,554 \mathrm{E}-02$ & 0,893 \\
\hline 5 & 0,271 & $\mathbf{0 , 8 6 0}$ & 0,312 & 0,910 \\
\hline 6 & 0,319 & $\mathbf{0 , 8 9 3}$ & 0,114 & 0,913 \\
\hline \hline & $\mathbf{0 , 6 6 7}$ & 0,246 & 0,511 & 0,766 \\
\hline \hline & $\mathbf{0 , 7 4 9}$ & 0,239 & 0,333 & 0,729 \\
\hline 10 & 0,116 & 0,514 & $\mathbf{0 , 6 6 9}$ & 0,725 \\
\hline 11 & 0,359 & $4,667 \mathrm{E}-02$ & $\mathbf{0 , 8 4 1}$ & 0,839 \\
\hline Eingenvalues & 0,217 & 0,444 & $\mathbf{0 , 7 4 2}$ & 0,795 \\
\hline \%) of Variance & 6,659 & 1,179 & 1,004 & \\
\hline
\end{tabular}

Kaiser-Meyer-Olkin Measure of Sampling Adequacy $(\mathrm{KMO})=0,731$ 
c) Elementos de custos de falhas internas

Esses elementos foram contemplados na pesquisa pelas assertivas de números 21 a 29, na análise fatorial denominada de componentes. Na Tabela 8 são mostrados os resultados.

Como se observa, o determinante da matriz de correlação é nulo, o que indica que não houve correlação suficiente entre as variáveis para que se pudesse aplicar a análise fatorial. Entretanto, ao se analisar as variáveis originais do ponto de vista qualitativo, identificou-se dois grupos principais, correspondendo a $80 \%$ da variância observada: um relativo a refugo e retrabalho, e outro referente às perdas por paradas de unidade ou atraso de produção.

Analisando a Tabela 8, de cargas fatoriais da matriz rodada, foi confirmada a existência de dois fatores, que mostraram ser os dois grupos de elementos de custo acima mencionados, representativos da categoria de custos de falhas internas. Haveria, portanto, dois fatores. O primeiro é composto pelas variáveis originais: a) perdas e refugo de produção; b) retrabalho; c) custo de mão-de-obra adicional devido

Quadro 1 - Fatores determinantes dos elementos do custo de prevenção.

\begin{tabular}{|c|c|c|}
\hline $\begin{array}{l}\text { ORDEM } \\
\text { DO FATOR }\end{array}$ & DENOMINAÇÃO & $\begin{array}{c}\text { VARIÁVEIS } \\
\text { DETERMINANTES }\end{array}$ \\
\hline 1 & $\begin{array}{l}\text { Melhoria contínua dos } \\
\text { processos e produtos, } \\
\text { visando à satisfação dos } \\
\text { clientes }\end{array}$ & $\begin{array}{l}\text { - Aprimoramento dos padrões de qualidade, objetivando a conformidade dos produtos } \\
\text { e serviços às necessidades dos clientes } \\
\text { - } \text { Planejamento e realização de testes de qualificação de novos produtos } \\
\text { - } \text { Avaliação do desempenho do produto em testes nos clientes } \\
\text { - Programa de treinamento em qualidade do pessoal operacional } \\
\text { - } \text { Desenvolvimento de novos processos e equipamentos }\end{array}$ \\
\hline 2 & $\begin{array}{l}\text { Avaliação da capacida- } \\
\text { de e do nível técnico de } \\
\text { fornecedores }\end{array}$ & $\begin{array}{l}\text { - Programas de revisão e avaliação dos contratos celebrados com os clientes, que afe- } \\
\text { tem as características de qualidade do produto } \\
\text { - } \text { Avaliação da capacidade dos fornecedores em atender aos requisitos de qualidade } \\
\text { - Revisão dos dados técnicos para a aquisição de materiais }\end{array}$ \\
\hline 3 & $\begin{array}{l}\text { Sistema de gestão } \\
\text { da qualidade }\end{array}$ & $\begin{array}{l}\text { - Desenvolvimento de novos fornecedores } \\
\text { - Elaboração e manutenção do manual da qualidade e de procedimentos operacionais } \\
\text { - } \text { Auditoria do sistema da qualidade }\end{array}$ \\
\hline
\end{tabular}

Tabela 7 - Custo de avaliação - Fator de carga (rotação: Varimax with Kaiser Normalization).

\begin{tabular}{|c|c|c|c|}
\hline COMPONENTES & FATOR 1 & FATOR 2 & COMMUNALITY \\
\hline 12 & $\mathbf{0 , 8 9 7}$ & 0,192 & 0,841 \\
\hline 13 & $\mathbf{0 , 9 0 1}$ & 0,240 & 0,870 \\
\hline 14 & $\mathbf{0 , 8 3 7}$ & 0,179 & 0,732 \\
\hline 15 & 0,314 & $\mathbf{0 , 6 7 4}$ & 0,553 \\
\hline 16 & $\mathbf{0 , 8 0 9}$ & 0,365 & 0,787 \\
\hline 17 & 0,193 & $\mathbf{0 , 7 5 6}$ & 0,608 \\
\hline 18 & 0,257 & $\mathbf{0 , 8 4 6}$ & 0,783 \\
\hline 19 & 0,181 & $\mathbf{0 , 8 4 6}$ & 0,749 \\
\hline 20 & $\mathbf{0 , 6 4 5}$ & 0,446 & 0,615 \\
\hline Eingenvalues & 5,151 & 1,386 & \\
\hline (\%) of Variance & 57,237 & 15,396 & \\
\hline
\end{tabular}

Kaiser-Meyer-Olkin Measure of Sampling Adequacy $(\mathrm{KMO})=0,840$ 
ao retrabalho; d) inspeção do produto retrabalhado; e e) disposição de material não-conforme. O segundo fator é composto pelas variáveis: a) custo financeiro do estoque adicional decorrente de produto não-conforme; b) perdas por parada da unidade ou atrasos de produção devido a falhas operacionais; c) perdas por parada da unidade ou atrasos de produção devido a falhas de equipamentos ou instrumentos de medida; e d) ações corretivas para evitar reincidência de problema de qualidade de produto ou serviço. $O$ Quadro 3 demonstra esses fatores e suas variáveis determinantes.

\section{d) Elementos de custos de falhas externas}

Esses elementos foram contemplados na pesquisa pelas assertivas de números 30 a 35, na análise fatorial denominada de compo- nentes. Na Tabela 9 são mostrados os resultados.

$\mathrm{O}$ valor de $\mathrm{KMO}$ igual a 0,530 indica uma adequação imprópria dos dados à análise fatorial. Foram identificados dois fatores representativos das variáveis originais que explicariam $70 \%$ da variância dos dados originais. O primeiro fator subjacente, com eigenvalue igual a 2,984, englobaria as variáveis: a) assistência técnica ao cliente; b) substituição de produto não-conforme recusado pelo cliente; c) avaliação de produto não-conforme devolvido pelo cliente; e d) pagamentos de indenizações aos clientes devido a problemas de qualidade. O segundo fator, com eigenvalue igual a 1,214 , representaria as variáveis: a) redução nas vendas em função de problemas de qualidade; e b) pagamentos de multas ou penalidades decorrentes de danos ambientais.

\section{Quadro 2 - Fatores determinantes dos elementos de custo de avaliação.}

\begin{tabular}{|c|c|c|}
\hline $\begin{array}{l}\text { ORDEM } \\
\text { DO FATOR }\end{array}$ & DENOMINAÇÃO & $\begin{array}{c}\text { VARIÁVEIS } \\
\text { DETERMINANTES }\end{array}$ \\
\hline 1 & $\begin{array}{l}\text { Análise de conformida- } \\
\text { de dos materiais às } \\
\text { especificações exigidas } \\
\text { na cadeia produtiva }\end{array}$ & 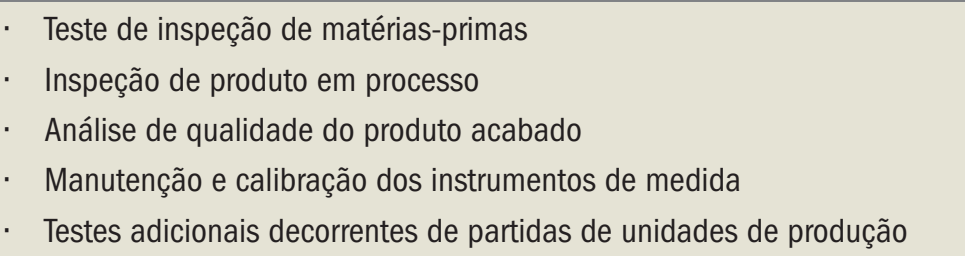 \\
\hline 2 & $\begin{array}{l}\text { Avaliação de desempe- } \\
\text { nho de materiais e de } \\
\text { produto }\end{array}$ & $\begin{array}{l}\text { - Amostras de produto ou material consumidas no controle de qualidade } \\
\text { - } \text { Depreciação dos instrumentos de medida } \\
\text { - Teste de qualificação dos produtos dos fornecedores } \\
\text { - Teste deção de desempenho do produto no cliente }\end{array}$ \\
\hline
\end{tabular}

Tabela 8 - Custos de falhas internas - Fator de carga (rotação: Varimax with Kaiser Normalization).

\begin{tabular}{|c|c|c|c|}
\hline COMPONENTES & FATOR 1 & FATOR 2 & COMMUNALITY \\
\hline 21 & $\mathbf{0 , 6 6 2}$ & 0,290 & 0,522 \\
\hline 22 & $\mathbf{0 , 9 0 1}$ & 0,328 & 0,919 \\
\hline 23 & $\mathbf{0 , 8 7 7}$ & 0,374 & 0,910 \\
\hline 24 & $\mathbf{0 , 9 4 9}$ & 0,215 & 0,947 \\
\hline 25 & $\mathbf{0 , 6 5 8}$ & 0,523 & 0,707 \\
\hline 26 & 0,476 & $\mathbf{0 , 7 3 5}$ & 0,766 \\
\hline 27 & 0,249 & $\mathbf{0 , 9 3 4}$ & 0,935 \\
\hline 28 & 0,249 & $\mathbf{0 , 9 3 4}$ & 0,935 \\
\hline 29 & 0,478 & $\mathbf{0 , 6 2 6}$ & 0,620 \\
\hline Eingenvalues & 6,126 & 1,134 & \\
\hline (\%) of Variance & 68,063 & 12,597 & \\
\hline
\end{tabular}

Kaiser-Meyer-Olkin Measure of Sampling Adequacy (KM0)

- matriz de correlação nula - determinante = zero 
No entanto, esse agrupamento não é coerente com a análise qualitativa das variáveis da categoria, evidenciando que, possivelmente, o número de dados observados é insuficiente para esse tipo de análise. Além disso, o baixo valor de KMO - igual a 0,53 - indica uma adequação imprópria dos dados. Para torná-los adequados à análise fatorial, Hair Jr. et al. (1998, p. 99) sugerem um exame particularizado das correlações parciais, isto é, a geração de uma matriz antiimagem de correlação. Neste estudo, não será feita a discussão dessa matriz, uma vez que, para o conjunto de elementos de custo referente às falhas externas, permaneceu a inferência evidenciada pela estatística descritiva demonstrada na Tabela 5.

\section{ANÁLISE DOS RESULTADOS}

Com relação ao objetivo principal, ficou evidenciado que 39\% das empresas do setor químico brasileiro tinham seu sistema de mensuração de custo da qualidade integrado aos sistemas de gestão de negócios.

Com relação aos objetivos específicos, pode-se depreender dos resultados da pesquisa que:

1) As empresas não utilizavam o sistema de custo como ferramenta de apoio à tomada de decisão, pois apenas 12\% das empresas evidenciaram que o utilizavam para melhoria do sistema, controle de custo e orçamento. Apesar do expressivo número de empresas certificadas pela norma ISO $9000 / 1994$, o sistema de custo não era tratado como fator estratégico na busca de vantagem competitiva.

2) A categoria de custos da qualidade mais significativa foi evidenciada pela falhas externas, com $53,4 \%$ das respostas atribuídas aos graus de importância "sempre" ou "quase sempre considerados". Esse resultado contraria o atual contexto da administração da qualidade, em que se deve prevalecer o controle dos processos internos para evitar

Quadro 3 - Fatores determinantes dos elementos de custos de falhas internas.

\begin{tabular}{|c|c|c|}
\hline $\begin{array}{l}\text { ORDEM } \\
\text { DO FATOR }\end{array}$ & DENOMINAÇÃO & $\begin{array}{c}\text { VARIÁVEIS } \\
\text { DETERMINANTES }\end{array}$ \\
\hline 1 & Refugo e retrabalho & 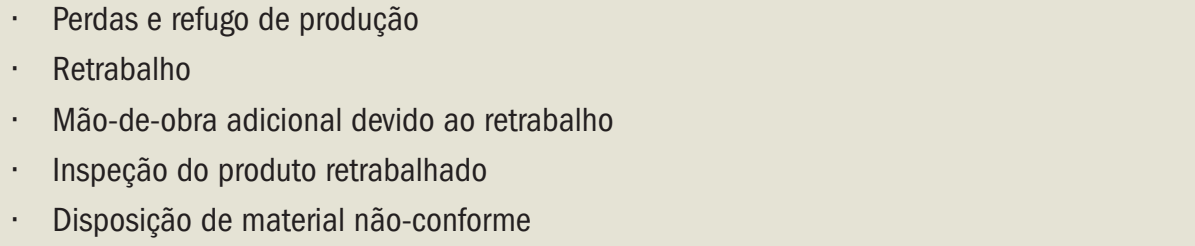 \\
\hline 2 & $\begin{array}{l}\text { Perdas por parada } \\
\text { ou atrasos de } \\
\text { produção }\end{array}$ & $\begin{array}{l}\text { - } \begin{array}{l}\text { Custo financeiro do estoque adicional decorrente de produto não-conforme } \\
\text { - }\end{array} \text { Perdas por parada de unidade ou atrasos de produção devido a falhas operacionais } \\
\text { ou instrumentos de medida } \\
\text { - }\end{array}$ \\
\hline
\end{tabular}

Tabela 9 - Custos de falhas externas - Fator de carga (rotação: Varimax with Kaiser Normalization).

\begin{tabular}{|c|c|c|c|}
\hline COMPONENTES & FATOR 1 & FATOR 2 & COMMUNALITY \\
\hline 30 & $\mathbf{0 , 7 8 0}$ & $-0,102$ & 0,619 \\
\hline 31 & $\mathbf{0 , 7 7 8}$ & 0,386 & 0,755 \\
\hline 32 & $\mathbf{0 , 5 4 4}$ & 0,502 & 0,548 \\
\hline 33 & 0,201 & $\mathbf{0 , 8 7 8}$ & 0,812 \\
\hline 34 & $\mathbf{0 , 8 0 6}$ & 0,216 & 0,696 \\
\hline 35 & $3,975 \mathrm{E}-02$ & $\mathbf{0 , 8 7 6}$ & 0,769 \\
\hline Eingenvalues & 2,984 & 1,214 & \\
\hline \%) of Variance & 49,726 & 20,240 \\
\hline
\end{tabular}

Kaiser-Meyer-Olkin Measure of Sampling Adequacy $(\mathrm{KMO})=0,530$ 
que os produtos ou serviços de má qualidade cheguem às mãos dos clientes (Deming, 1990).

Para os elementos de cada categoria de custos da qualidade, extraiu-se da análise fatorial: 1) para o custo de prevenção, os fatores determinantes (a) melhoria contínua dos processos e produtos, visando à satisfação dos clientes; (b) avaliação da capacidade e do nível técnico dos fornecedores; e (c) sistema de gestão da qualidade, com ênfase na garantia da qualidade; 2) para o custo de avaliação, os fatores determinantes (a) análise de conformidade dos materiais às especificações exigidas na cadeia produtiva; e (b) avaliação de desempenho de materiais e de produtos; 3) para o custo de falhas internas, os fatores determinantes (a) refugo e retrabalho; e (b) perdas por paradas ou atraso de produção; e 4) para o custo de falhas externas não foram evidenciados fatores principais ou subjacentes, pois os fatores observados não eram coerentes.

3) As empresas atribuíam pouca ênfase ou importância ao sistema de mensuração do custo da qualidade, visto que 23\% delas possuíam indicadores de desempenho qualitativo e quantitativo e de custos de qualidade, e apenas 14\% tinham um sistema de mensuração de custos da qualidade implantado.

Os resultados deste estudo são válidos para as empresas da amostra analisada. Ressalve-se, porém, que, no momento destas conclusões, a Abiquim /Qualiquim identificava em seu quadro de associadas que $80,5 \%$ possuíam certificação ISO $9000 / 1994$ e 13\% estavam em fase de sua implantação. Comparando-se esse percentual, 80,5\%, com o evidenciado pelas empresas que responderam ao questionário, $76 \%$, constata-se que é possível estender o resultado apurado à população amostrada nesta pesquisa.

\section{CONCLUSÕES E SUGESTÕES PARA PROSSEGUIMENTO}

\section{Conclusões}

Este artigo consistiu de uma pesquisa, cujo projeto se iniciou em 1998. Naquele ano, a estabilização econômica e o ambiente empresarial competitivo faziam com que a gestão da qualidade total das empresas emergisse como de fundamental importância para a satisfação de seus clientes, por meio do incremento dos níveis de qualidades dos serviços prestados e da redução dos custos de seus produtos.

Assim, condizente com a filosofia abordada pela gestão da qualidade total, a mensuração dos elementos de custo da qualidade deveria ser contemplada como uma ferramenta gerencial no apoio às decisões administrativas.
Idealizou-se, então, realizar a pesquisa em um segmento industrial de representatividade econômica no cenário nacional, em que $76 \%$ das empresas respondentes eram certificadas pelas normas da série ISO $9000 / 1994$, conforme foi confirmado pelos questionários devolvidos.

Assumiu-se, por isso, a premissa de que as empresas, possuindo um sistema de gestão da qualidade, teriam estruturado, também, um sistema para a mensuração dos elementos de custo da qualidade.

Sob esse enfoque, as conclusões significativas foram as seguintes: 1) 39\% das empresas evidenciaram que o sistema de mensuração de custos estava integrado aos sistemas de negócios vigentes; 2 ) esse sistema não era utilizado como ferramenta de apoio para as decisões estratégicas; 3) a categoria de custo de falhas externas foi o mais significativo; e 4) o sitema de mensuração de custos não ocupava posição de destaque, mesmo para empresas que tinham sistema de garantia da qualidade implantado.

Finalmente, a individualização e o conhecimento dos custos da qualidade e de sua dinâmica podem fornecer aos administradores empenhados em projetos de melhoria contínua da qualidade uma contribuição estrategicamente determinante, uma vez que eles permitem a comparação contínua entre os custos de entrada relativos aos investimentos e os custos de saída relativos aos resultados obtidos em termos do desempenho dos controles de custos da má qualidade, como as falhas internas e externas. Evidentemente, a implementação de um sistema de controle dos custos da qualidade empresarial é eficaz e significativo somente se for inserido em um contexto integrado, que tenha a busca da qualidade como um objetivo primário ou fundamental.

As literaturas técnicas, bem como as recentes normas de controle, enfatizam que a instauração de um sistema de gestão dos custos da qualidade deve envolver o levantamento dos problemas, sua análise e interpretação, e tomar o cuidado de não criar sistemas artificiais ou extremamente formalizados ou articulados, que causem a perda da motivação que levou à criação do próprio sistema.

Portanto, um sistema de custos da qualidade a ser implementado deve ser acessível e inspecionável, tanto pela parte administrativa da organização quanto pelo gerente. Deve, também, ser sistemático, planejado diante de padrões precisos e inserido na normal vida contábil da administração.

\section{Sugestões para prosseguimento}

Os resultados obtidos permitem sugerir algumas sugestões para se conseguir um melhor aproveitamento do sistema de mensuração dos custos da qualidade: 1) adotar indicadores de desempenho da qualidade tendo como base o benchmark. Exemplo: a questão que abordava o tipo de 
indicador de desempenho da qualidade sugere a aplicação de benchmark na implantação de um sistema de mensuração de custo para o setor químico pesquisado, visto que apenas 23\% das empresas que responderam aos questionários adotavam medidas quantitativas com valor de custo da qualidade; 2) dar maior atenção aos processos internos, evitando os custos de falhas externas e seu posterior prejuízo quanto à imagem e mesmo quanto à perda de fatia de mercado por parte da empresa; 3 ) investir em treinamento dos funcionários e em aprimoramento contínuo dos processos de fabricação, com ênfase em prevenção, que tenham como conseqüência a redução dos custos de falhas internas e externas; 4) investigar se, com a adoção da norma de qualidade versão ISO 9001 /2000, o sistema de mensuração de custos da qualidade ganhou destaque ou importância no sistema de gestão de negócios da empresa, uma vez que o sistema de mensuração de custos da qualidade é um item obrigatório para se obter a certificação ISO 9001 /2000; e 5) incluir no questionário os dados financeiros ou mesmo os dados qualitativos, como as resultantes de entrevistas. Esses dados poderão contribuir significativamente para uma maior confiabilidade nos resultados obtidos.

Ciente dos resultados desta pesquisa, a Abiquim/ Qualiquim projetou a realização de um workshop para viabilizar áreas de interesse administrativo e de melhoria contínua, considerando, também, a mudança prevista para as normas da série ISO 9001 /2000 (Abiquim, 2002, p. 22), em vigor a partir de 2002.

Recebido em 11.06.2002. Aprovado em 06.02.2003.

\section{Referências bibliográficas}

ABIQUIM - Associação Brasileira da Indústria Química e Produtos Derivados. Relatório anual. São Paulo : Abiquim, 1997, 2000 e 2002.
ABNT - Associação Brasileira de Normas Técnicas.nCB 25 (Comitê Brasileiro de Qualidade).

ANFAVEA - Associação Nacional dos Fabricantes de Veículos Automotores. Anuário estatístico da indústria automobilítica brasileira. São Paulo : Anfavea, 2002.

CHRISTOPHER, Martin. A logística do marketing. São Paulo : Futura, 1999 CROSBY, Philip B. Qualidade é investimento. $7^{\mathrm{a}}$ ed. Rio de Janeiro : José Olympio, 1999.

DEMING, William Edwards. Qualidade: a revolução da administração. Rio de Janeiro : Marques-Saraiva, 1990.

EASTERBY-SMITH, Mark, THORPE, Richard e LOWE, Andy. Pesquisa gerencial em administração. São Paulo : Pioneira, 1999.

FALCONI CAMPOS, Vicente. TQC - Controle da qualidade total. $2^{a}$ ed. Belo Horizonte : Desenvolvimento Gerencial, 1999.

FEIGENBAUM, Armand V. Controle da qualidade total. São Paulo : Makron Books, 1994

HAIR JR, Joseph F., ANDERSON, Rolph E., TATHAM, Ronald L. e BLACK, William C. Multivariate data analysis. New Jersey : Prentice Hall, 1998.

HEIZER, Jay e RENDER, Barry. Administração de operações - bens e serviços. Rio de Janeiro : LTC, 2001.

INMETRO. Cerificados ISO 9000 por ano calendário. 2002. Diponível em: <http: Nwww.inmetro.gov.br>.

JURAN, J. M. e GRYNA, Frank M. Controle da qualidade: conceitos, políticas e filosofia da qualidade. São Paulo : Makron Books, 1991.

MALHOTRA, Naresh K. Pesquisa de marketing, uma orientação aplicada. Porto Alegre : Bookman, 2001.

OSTRENGA, Michael R., OZAN, Terrence R. e McILHATTAN, Robert D. Gestão total dos custos. Guia da Ernst \& Young. Rio de Janeiro : Record, 1993

ROBBINS, Stephen P. Administração - mudanças e perspectivas. São Paulo Saraiva, 2000.

SAKURAI, Michiharu. Gerenciamento integrado de custos. São Paulo : Atlas, 1997

SBQ - SISTEMA BRASILEIRO DA QUALIDADE. Banas qualidade. São Paulo, edição especial, 1998 /1999 /2000.

\section{Roberto Giro Moori}

Professor do Programa de Pós-Graduação em Administração de Empresas - MACKENZIE (PPGAE). Doutor e Mestre em Engenharia de Produção pela Escola Politécnica da Universidade de São Paulo. Interesses de pesquisa: Gestão da Cadeia de Suprimentos, Gestão em Redes de Negócios, Operações, Qualidade e Produtividade.

E-mail: rgmoori@mackenzie.com.br

Endereço: Rua da Consolação, 896, $7^{\circ}$ andar. São Paulo, SP. CEP 01302-907.

\section{Rubens Vieira da Silva}

Professor de Graduação em Administração de Empresas. Doutorando em Engenharia pela Escola Politécnica da Universidade de São Paulo. Mestre em Administração de Empresas pela Universidade Presbiteriana Mackenzie. Interesses de pesquisa: Qualidade e Produtividade, Administração da Produção e Sistemas Integrados de Gestão. E-mail: maluvi@terra.com.br

Rua Engenheiro Isaac Milder, 355. Parque Real. São Paulo, SP. CEP 05688-010. 